Article

\title{
Design Thinking for Urban Water Sustainability in Huelva's Households: Needfinding and Synthesis through Statistic Clustering
}

\author{
Gustavo Bermejo-Martín, Carlos Rodríguez-Monroy *(i) and Yilsy M. Núñez-Guerrero \\ Department of Industrial Organization, Business Administration and Statistics, E.T.S. Ingenieros Industriales, \\ Universidad Politécnica de Madrid (UPM), Calle José Gutiérrez Abascal 2, 28006 Madrid, Spain; \\ gustavo.bermejo.martin@gmail.com (G.B.-M.); ym.nunez@upm.es (Y.M.N.-G.) \\ * Correspondence: carlos.rodriguez@upm.es
}

Received: 22 July 2020; Accepted: 1 November 2020; Published: 4 November 2020

\begin{abstract}
This article shows the numerical results and the analysis of households' degree of knowledge about the urban water cycle, needs, and values regarding water in an intermediary city with low water stress, such as Huelva (Andalusia, Spain). Results are also presented regarding how households maintain the acceptance of reclaimed water and new technologies to achieve more efficient and sustainable consumption. Surveys were sent to households, and different statistical analysis techniques were applied. The use of clustering as a mathematical tool has served to obtain three clusters of households with similar characteristics with respect to the previous factors. The first cluster corresponded to households with high knowledge of the integral water cycle and positive attitude to smart devices at home. The second cluster showed low knowledge of the integral water cycle and high sensitivity to price. The third one had average knowledge and predisposition to have a closer relationship with the water company. This classification allows implementing different water demand management strategies tailored to each cluster. Applying a Design Thinking methodology, a web-based prototype has been designed as an ICT tool concerning households. The goal is to achieve greater engagement of households concerning water and align citizens with their city's sustainability.
\end{abstract}

Keywords: Design Thinking; hydrosocial contract; web-based prototype; household engagement; Product Service Systems; clustering; ICT; sustainable use of water; customization

\section{Introduction}

This article shows the numerical results and the analysis of households' degree of knowledge in an intermediary city such as Huelva (Andalusia, Spain) about sustainable urban water use. Besides, it analyzes the needs and values regarding water and the attitudes that households maintain regarding the acceptance of reclaimed water and new technologies to achieve more efficient and sustainable consumption. It is not a dynamic, forecasting study, just a static, descriptive analysis that is a first approximation to characterize the basis to develop successive steps within the research.

Based on knowledge, values, and needs, the purpose of this research is to achieve a clustering of households. This classification is the essential starting point to build a web-based prototype within a Design Thinking (DT) methodology. This prototype intends to extract learning lessons to implement an effective water demand management (WDM). WDM strategies will be tailored to each cluster.

Within the WDM there are three types of strategies, which can be combined in different proportions and forms [1]:

1. The application of technology.

2. The use of economic levers, basically the price. 
3. The promotion of changes in consumer behavior and habits.

Through different experiments, with different proposals per cluster, the most appropriate combination of feedback strategies, price, and the use of technological facilitators will be tested. The goal is to achieve greater engagement of households concerning water and align citizens with sustainability in Huelva.

Regarding the context to be able to apply WDM strategies, one of the novelties of this paper with respect to other similar studies is that it has been carried out in a city like Huelva, of intermediate size, which presents a category of low water stress. Other studies have focused on large cities and megalopolis, which present high water stress or water scarcity. This scarcity of water constitutes a powerful driver to achieve citizen engagement regarding water. However, would it be possible to achieve citizen engagement in a context where there is no water crisis?

On the other hand, the irruption of new technologies and information and communication technologies (ICT) has had an impact on the fact that water, supply, demand, and management are just a click away from smartphones or computers. This opens a new door for what has come to be called the digital citizen, who aspires to live in a smart city. ICTs facilitate citizens' engagement and allow them to interact with institutions and companies through these tools [2].

The scope of household participation in this paper is that of e-consulting. This type of participation is "a limited two-way channel that has the objective of collecting public feedback and alternatives" [3].

Good access to ICT is required for this research and for the subsequent steps derived from it. This is the reason for introducing in this section a brief review on some important aspects of ICT in Spain. On the other hand, regarding technological facilitators, one of the most important is having an adequate telecommunications infrastructure [4]. Besides, the accessibility of households to infrastructure, technology, and services available on said infrastructure and the technological skills for such use are other critical factors [5]. As a summary, the situation in Spain regarding ICT, in July 2019, according to the National Commission for Markets and Competition (CNMC) report [6], was:

1. $67.9 \%$ of the telecommunication lines had download speeds higher than $100 \mathrm{Mbps}$. In Europe, the situation was $33.7 \%$ of the lines.

2. Spain ranks fourth in Europe with the highest percentage of lines with high-speed service.

3. Regarding households' particular situation in Spain, the percentage of households with Internet services was $89.7 \%$, and those with fixed broadband represented $82.7 \%$ of the total.

4. Approximately $73 \%$ of Spaniards connect to the Internet every day, and $48.3 \%$ consume online content at least once a week.

5. The mobile telephony park stood at 55.4 million.

6. Mobile telephony reached a penetration rate of 117.9 lines per 100 inhabitants.

In all the previous points, growth was achieved compared to 2018. In Huelva, as in the rest of Spain, there is an optimal situation regarding ICTs and their use by households, which allows the usage of technological facilitators as tools to implement WDM strategies. Therefore, Spain's ICT situation makes it possible to scale this experience to other parts of the Spanish territory.

In addition, there is a firm commitment by the Spanish State to provide Spanish cities with an ICT infrastructure. This is the National Plan for Smart Cities, where there have been several calls to meet the cities' demands. "It constitutes one of the mainstays of the Digital Agenda for Spain and has a budget of 188 million euros. Its objective is to improve the effectiveness and efficiency of local entities in the provision of public services through ICTs and to advance the Smart City and Tourist Destination system. It results in a better quality of life for citizens, a greater interaction of these with the environment and an increase in the saving of energy and environmental resources" [7].

Regarding WDM strategies focused on achieving changes in consumer behavior and habits, this paper considers citizens' central role in designing solutions for sustainable development of cities relating to water, expressing itself through private behavior using water in households. Previously, we analyzed how water was considered for integrated sustainable urban development and citizens' 
needs, from the different public administrations, through the approved Integrated Sustainable Urban Development Strategy (ISUDS) plans in the Andalusian region [8]. The citizens are one of the main stakeholders in the elaboration of the ISUDS. "In a way, these plans are expressions of citizens' public behavior concerning water, their values, and their needs" [9]. The focus of these two analyses would give us a picture of the common patterns and coherences between the two spheres of the citizen, public and private [10]. Private behavior would measure citizens' social needs [11], focusing on real habits of comfort and cleanliness [12].

To get citizen participation, we use DT, a human-centered methodology that creates a framework to support actions and relationships between the water utility and households. There are some examples of using DT methodology to get engagement, as in the case of the Austrian gas company Redgas, a subsidiary of Linz AG [13]. This company followed the recommendations of Meyer and Tucker [14] to understand better customer needs and behavior.

On the other hand, Yan, and Roggema [15] bet that design solutions reflect action programs for the UN Sustainable Development Goals (SDGs) with the cooperation of producers, citizens, and governments, aligning their respective interests of economic benefit, better living environment, and improvement of efficient public services (in this order). Pruneau et al. [16] showed numerous examples of how DT has been incorporated into producing sustainable solutions that lead to sustainable development.

A key issue in improving the water company's trust is obtained through the service brand [17]. To support the educational activities carried out in other successful projects [18], trust and the improvement of the sustainability challenge's understanding, are critical factors. "Therefore, it seems clear that actions must be brought into play that improves the perception of the service brand by households to increase household trust in the proposed future actions" [9].

There is a myriad of DT methodologies [19]. We have used the six stages defined in the Stanford ME310 model [20]. Given this variety of methods, and in order not to dwell on them too much, we have found that it is interesting to introduce a brief summary of the Stanford model in Figure 1. In this way, we clearly delimit the stages covered in this paper. For the goals of this paper, we will focus on:

1. Needfinding: The interviewing method has been used. This is the first in the ranking of [19]. "We conducted in-depth interviews with different specialists from the company Aguas de Huelva who gave us the vision of the utility: the director of innovation and social responsibility, the commercial director, and the general manager" [9]. With this feedback, we elaborated a 28-question survey for households to know their needs, values, knowledge of the integral water cycle, and water use in their homes. We sent surveys to households that agreed to participate in the experiments.

2. Synthesis: The clustering method was chosen first in the ranking of [19]. Using the statistical analysis of the survey responses, we have tried to obtain different household profiles in the way of those obtained in [10], which allows us to do a sustainable solution customized to each profile.

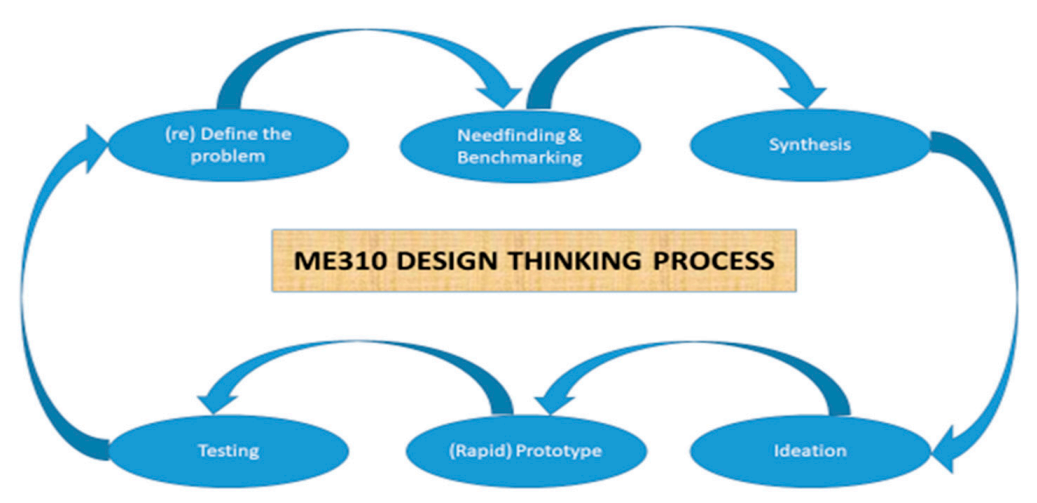

Figure 1. Stanford ME310 model. Adapted from [20]. 
The citizens' needs are embedded in a specific city context, where the citizens try to satisfy them through the water company services. Depending on the needs covered by the services already deployed and on the existing hydrosocial contract and the relationship between habitability [21] and sustainability [22], some strategies could be implemented to achieve the citizens' engagement.

"The hydrosocial contract is understood as the values and, often, implicit agreements between communities, governments, and businesses on how water can be used. This hydrosocial contract will reflect citizens' practice and behavior in water use within the city and the needs and mechanisms used to satisfy them" [9].

The hydrosocial contract is expressed on how the environment is organized (de Haan et al. [23]). For the physical environment, technology is required, and the resulting organization is the infrastructure on which the services are provided. The social organization is made through rules, habits, and routines, and its resulting institutions. In society's systems, there is a combination of institutions and infrastructures within the city, which defines their degree of intelligence. In the case of urban water, in addition to the gray infrastructure itself (classical water engineering), natural infrastructures (rivers, lakes) and green infrastructures (wetlands) are included. In these infrastructures, water services are provided in the cities.

Based on the theory of Educational Psychology, Dean et al. [10] propose a methodological framework developed in the socio-cultural context, which elaborates three pillars of the citizens' commitment to their city's water, as can be seen graphically in Figure 2:

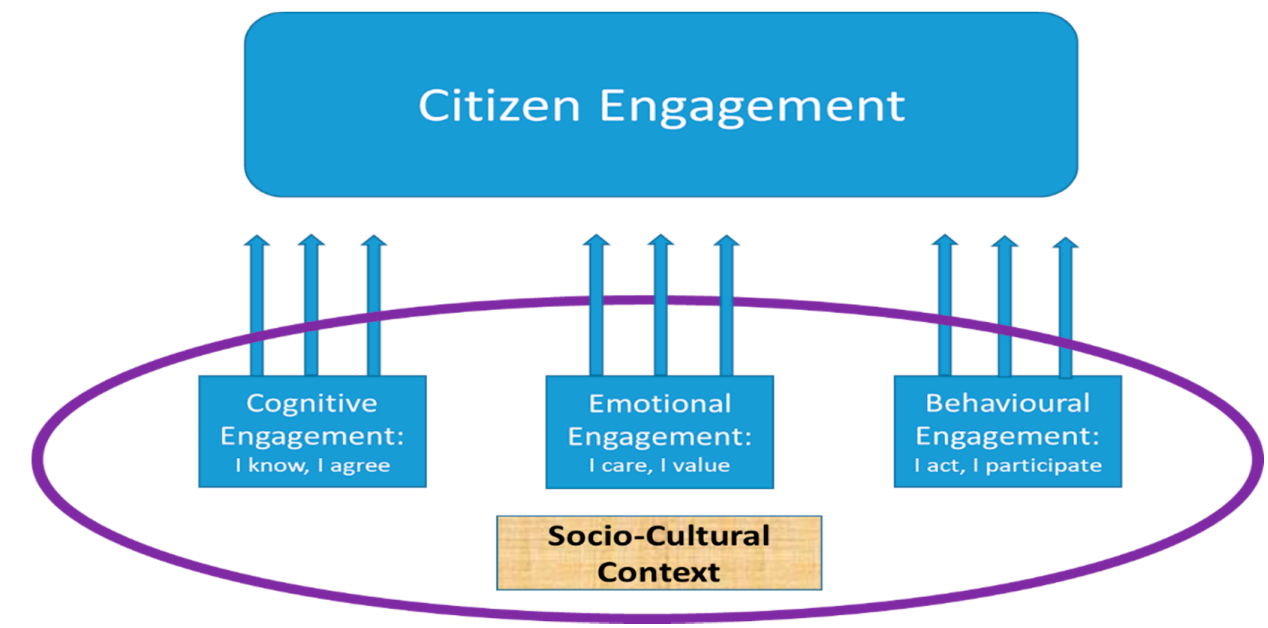

Figure 2. Methodological framework to evaluate the commitment regarding water. Adapted from Dean et al. [10].

1. Understand water and its context. That is, the knowledge possessed about water.

2. Value water through emotions and the development of positive attitudes, such as:

a. Support for alternative sources of water.

b. Pro-environmental attitude: the environmental identity of the home.

3. Support the smartest daily behavior regarding water in different spheres

a. Public:

i. Through the influence on political processes.

ii. Support and pressure to repair damaged waterways.

b. Private:

i. By saving and using water efficiently.

ii. Using of water-saving devices.

iii. Reducing water pollution. 
For this article's purposes, only the private sphere of citizens' behavior will be considered a research proposal. This daily behavior directly relates to the habit created in the daily use of water in homes to meet the needs mentioned above. Habit, according to Bourdieu [24], occurs in a social context and according to an accumulated capital of knowledge and material wealth of households. Bourdieu's idea connects with the methodological framework of educational psychology, which seeks to change this habit through the pillars of knowledge and valorization. This is not immutable and less in current societies where changes are continually occurring, but the habit does have an internal limit in its original structure within contours of continuity that allow it to vary up to certain limits. Therefore, it is necessary to determine strategies, methods, and technological tools to change habits or bring current dominant habits to their limits. In addition, as part of that accumulated capital of households, there are the domestic technologies and the devices with which they interact to meet their needs. These strategies and methods can be enhanced through technology, which, when used well, will act as a tool for empowerment and increase the commitment of citizens to the use of resources, in our case, water.

This habit guides the behaviors of comfort and hygiene, which are those that consume more water in homes. Depending on the study, the figures vary slightly from one to the other. However, we can take the data from Knoeri et al. [25], which indicate that in the United Kingdom, the water used inside households goes mostly to hygiene services, where $33 \%$ of the water is for personal hygiene (bathrooms, showers, hand-washing), $30 \%$ for flushing the toilet, and $13 \%$ for washing clothes. The habit of consumption that is part of households' domestic daily lives has a very high impact on the water resource.

According to Strengers [12], an increase in comfort and hygiene expectations occurs in the western world. This increase stresses the balance between habitability and sustainability, between real or perceived need and resources needed to satisfy it and condition the citizen's real commitment. Managing the citizens' expectations and daily behavior regarding water is part of the WDM strategies, which should be personalized to each household type.

\section{Materials and Methods}

Both the scope of the challenge to be solved, and the city chosen to carry it out, determine the materials and methods to be used. The state and deployment of the city's water network infrastructure, the ownership structure of the water company responsible for the service, the available ICTs, the weather, the social composition according to the districts, and the hydrosocial contract from which we start, are factors, among others, that constitute a limiting context for the development of this section of the paper. It is important to describe this context to properly calibrate the possible replication of the research in other parts of the world.

The Suez group through the UP4 Solutions program, in collaboration with the UP4 technological universities alliance (Universitat Politècnica de Catalunya, Universidad Politécnica de Madrid (UPM), Universitat Politècnica de València, Universidad Politécnica de Cartagena) [26] defined a challenge to get a more efficient and sustainable use of water in homes.

"The main objective of the challenge is to promote the efficient and sustainable use of water resources based on information, communication, and awareness of citizens. The project focuses on understanding, within the water cycle, what are the factors, elements, and data that generate the greatest impact and understanding of the challenges faced in terms of water resource management, thus being able to generate a reflection of households towards a cultural change regarding their use and valorization" [9]. Specific goals have been defined:

1. Evaluate the degree of knowledge of consumers about the challenges associated with the sustainable use of water.

2. Identify their needs and values as consumers.

3. Evaluate attitudes towards different aspects of water: 
a. Attitude towards consumption efficiency.

b. Attitude towards the adoption of technological devices in the home related to water.

c. Attitude towards reclaimed water in the home.

4. Determine prototype solutions that help raise awareness and value water use sustainability, proposing specific actions to consumers that address part of their needs at the same time.

"This should help to directly relate the day-to-day behavior of Huelva's households with the sustainability of comprehensive water management. In this way, it is intended to promote a change in consumer behavior, which, together with the efforts of the managers of the urban water cycle (Aguas de Huelva), should lead to more sustainable use and better protection of current and future resources" [9].

The Suez group designated Aguas de Huelva as the utility to carry out the project. "The city of Huelva, in Andalucía (Spain), has approximately 140,000 inhabitants (intermediary city). Aguas de Huelva has around 52,000 clients, most of whom are households. These clients are distributed in six districts that show social homogeneity. Of the 52,000 clients, 9350 of them receive a digital invoice, from which it can be deduced that they are accustomed to using ICT tools, such as email, SMS, APPs, and web browsing and have sufficient technological infrastructure (computers, tablets, smartphones, and telecommunications connectivity) to communicate with them through digital channels" [9].

Aguas de Huelva is a company where $51 \%$ belongs to the Huelva city council, and $49 \%$ belongs to the Suez group [27]. "Urban water services, the direct public responsibility of each city council, in most Spanish cities are carried out through a water utility that is either entirely private through commissioning or mixed public-private ownership" [9].

Huelva has four main urban challenges that affect water: demographic stagnation, social diversity, climate change, and unstable and unpredictable water social needs [23]. They present a high social diversity, which will demand management strategies with very different approaches for their efficiency, according to Dean et al. [10].

In collaboration with Aguas de Huelva, a plan based on DT methodology was approved in July 2018. This methodology constitutes the general model or research framework, where specific methods are developed and applied in each phase. The paper covers the stages of needfinding and synthesis of DT. The time scope was set up for one year to avoid the seasonal effect of Spain's natural water cycle. Due to many factors to be considered, such as logistics reasons, costs, and time, among others, a sample goal of households in a range between 200 and 300 households was targeted.

"The plan contemplates three phases:

1. Measurement of the starting point of households in Huelva regarding the three axes of knowledge, needs, and water valuation using a survey via email.

2. Proposal for a web-based prototype to measure the impact of actions in the three previous axes (touch-points with households) to increase water engagement.

3. Workshops with households to qualitatively measure their evaluation of the prototype and possible improvements to incorporate into a new prototype, the last one, before the final launch of the web-based solution" [9].

To cover DT's needfinding phase, feedback from Aguas de Huelva and the Suez group of experts was collected, with which we elaborated a 28-question survey for households to know their needs, values, knowledge of the integral water cycle, and water use in their homes. In addition, the available scientific documentation was reviewed and the model applied in the research by Dean et al. [10] was chosen, as it seemed the most reliable and adapted to the research context, whose focus is to determine the Community profiles of engagement in water-related issues. This model follows a methodology based on the survey questions' design, the sending of the said survey, and the mathematical analysis of the household survey data. In addition, this model also made it possible to cover the DT synthesis phase by means of clustering groups of households based on needs valorization and similar behaviors. We followed the same methodology as Dean et al. [10] to select the variables and their categorization that allowed to generate and characterize the different clusters. This statistical classification technique 
allows extracting common patterns for groups. It could help customize different demand management strategies for each group and convey personalized messages to each group for being more effective in citizen engagement concerning water. This research is not a dynamic, forecasting study. It is just a static, descriptive analysis, a first approximation to characterize the basis for developing successive steps within the research.

Other research projects on household resource consumption follow a similar methodology, highlighting the use of surveys and similar statistical analyses, which confirms the materials and methodology used here. Among them, we can highlight [28] on environmental lifestyle, [29] on community knowledge about water, [30] with the use of mixing quantitative and qualitative research approaches and processes on end-use water consumption in households, [31] on the use of surveys and case studies of an Australian water utility, and [32] regarding individual householder survey responses to predict household environmental outcomes.

Regarding the generation of clusters, there are also studies focused on the end-use of household water consumption such as [33]. It seems appropriate to use the cluster analysis technique, as it is an exploratory data analysis tool to get groups of individuals with similar characteristics. Clustering has been applied in two phases, partitioning and interpretation. "The partitioning stage is the process of determining the number of clusters that may be developed. The interpretation stage is the process of understanding the characteristics of each cluster" [33].

Cluster analysis methods can be divided into hierarchical and non-hierarchical ones. Applying hierarchical methods, clusters can emerge from the data, and it is suitable for limited data available to pre-identify groups. Non-hierarchical methods need to know a priori the number of clusters that will be obtained as result of the analysis [34].

Within the hierarchical methods, one of the most reliable and used tools is Ward's method. In case studies like ours, where there are no clusters identified a priori, Ward's method is preferable to other analysis techniques such as non-hierarchical methods. Among the latter, the k-means algorithm and the Expectation Maximization (EM) stand out [34]. This choice of methodology has also been followed in [10]. In this research, Dean et al. chose the hierarchical cluster analysis procedure, using Ward's method, and squared Euclidean distance. It represents a structure of hierarchically ordered clusters in a treelike structure or dendrogram. It is a very visual tool that gives an approximation of heterogeneity change for all combinations of clusters. "Distances between clusters in this method are determined according to an analysis of variance, which aims to minimize the sum of squares within clusters" [35].

Mathematically, the maximum number of clusters is reached when the different combinations do not produce significant improvements in heterogeneity between clusters. This procedure allows quickly, through the cluster centroids, to describe the general characteristics of a cluster, which explains the homogeneity of the cluster. Centroids are the mean values for each item [33].

The decision on the maximum number of clusters has to take into account the mathematical criteria described. However, other additional factors appear in later phases of the project. These factors can be logistical, operational, and cost restrictions, among others. They appear when field experiments based on WDM strategies are applied to the clusters obtained.

Clustering is a technique that could be more suitable for today's cities, with very dynamic societies and a broad myriad of knowledge, values, and behaviors. Thus, there is a need to use more targeted strategies, more differentiated, personalized, and better built according to each household profile. Strategies that can be facilitated include scaling the research pilot to all homes in the city, using ICT and mathematical techniques as Artificial Intelligence (AI), Big Data Analytics (BDA) [36], and Artificial Neural Networks (ANN). The availability of these technologies can enhance the scope of this research in other parts of the world and constitute a means of expanding it qualitatively and quantitatively.

Communication is a key issue in achieving customer engagement because it is necessary to generate new messages and meanings regarding water, acting in the semantic dimension, and the functional dimension (technology) of water [37]. Changing people's behavior is a complex challenge, and it needs a radical design-driven innovation approach [38], managing symbolic and functional 
factors that influence individual water use patterns. Hence, our project's semantic dimension is critical to generate our future prototype to interact with households (web-based prototype) [39], since the graphic part and the web-customer relationship interface should be taken care of. This constitutes a key material for other stages of the research, the design of which will be conditioned by the characteristics of the clusters obtained as a result of this article. Therefore, it is a factor to take into account at this stage for later phases, and its importance should be highlighted. Wicked problems are too abstract, difficult to communicate with words, so it is mandatory to have an excellent graphical interface with households [40].

In summary, the plan contemplates a first phase that corresponds to a study of the knowledge that households have of the integral water cycle and the values and relationships concerning water. This is an exploratory and descriptive investigation. These parameters will be measured through a survey with 28 questions to respond by households in about $30 \mathrm{~min}$. "The survey questions were reviewed by 15 experts from Aguas de Huelva, making various modifications and eliminating some of the original questions proposed by the UPM team. This was done during September 2018. The means to make it reach the citizen would be through email with a link to the Aguas de Huelva web site where the survey is placed" [9]. The questions/answers will follow a 5-level Likert scale, associating them with major factor blocks:

1. Demographic characteristics: Collected in the first five questions such as age, gender, education, annual income, and professional occupation.

2. Home characteristics: Number of people in the household, children in the home, surface area, age. These questions go from number 6 to 9 (both included).

3. Life experiences and psychosocial factors: Household activities around the city water, active participation in any social organization, and if they have suffered any water restriction. They are questions 10, 11, and 12.

4. Needs, values, and identity regarding water: The importance of different aspects of water, consumption concerning neighbors, identification of better use of water within the home, the possibility of the investment amount in water-saving devices, and acceptance of water regenerated in the home (support to alternative sources of water). Questions 13 to 18.

5. Knowledge of the home regarding the integral water cycle. The questions are ordered in the following blocks:
a. Uptake: Questions 19 and 20.
b. Treatment: Question 21.
c. Distribution: Question 22.
d. Sewerage networks: Questions 23 and 24.
e. Purification: Questions 25 and 26.
f. Regeneration: Questions 27 and 28.

"The commitment of participation of 120 households was achieved. In December 2018, the survey was launched via email with a link to questions to the 120 participating households. Finally, in mid-June 2019 , after several rounds of survey submissions, the survey response collection process was closed with a total of 97 valid responses from participating households" [9].

The responses were coded. In this coding stage, the following fields provided by Aguas de Huelva were added to the response table:

1. Huelva area to which the home belongs: Six possible ones that correspond to the social districts that the Huelva City Council applies to the city.

2. Average consumption per person within the home: Liters/person/day. They correspond to the average of the year 2018 . 
3. Consumption range of each household, according to this classification agreed with Aguas de Huelva:
a. Less than $100 \mathrm{~L} /$ person/day is low consumption.
b. Between 100 and $130 \mathrm{~L} /$ person/day is an average consumption [41].
c. More than $130 \mathrm{~L} /$ person/day is high consumption.

The consumption range was set, taking into account that:

1. The average consumption per inhabitant per day in households managed by Aguas de Huelva is 126.5 L/inhabitant/day.

2. The minimum vital water consumption set by the World Health Organization is set between 50 and $100 \mathrm{~L} /$ inhabitant/day [42].

Surveys have been statistically processed using IBM SPSS v. 25.

\section{Results}

The analysis of the data obtained through the survey's application that contributes to answering the research objective is presented. Results are structured according to three-factor blocks: Demographic characteristics, household characteristics, life experiences and psychosocial factors.

Concerning the household's knowledge regarding the integral water cycle, each correct answer was given a value of 1 , and each incorrect answer value of 0 . The maximum score, therefore, that could be obtained was 10 points. These scores were grouped in the following ranges:

1. Low knowledge range: Scores less than 4.

2. Average knowledge range: Scores between 4 and 6 .

3. High knowledge range: Scores equal to or greater than 7 .

Taking the global score over 10 possible points, and the previous rank classification, the following results were obtained:

1. A low range of knowledge: 30 households.

2. An average range of knowledge: 57 households.

3. A high knowledge range: 10 households.

On 10 possible points, the average of total knowledge gives a score of 4.2577 , which indicates a degree of knowledge of the integral water cycle close to that approved, that is, a degree of average knowledge, but still deficient in some of the stages.

Besides, it can be seen that the question that presents the least number of correct answers is the one referring to the sewerage system of the network, question 24, where there are only eight correct answers. However, 71 households correctly answer question 23 about the water sanitation system.

In contrast, the question with the highest number of positive responses is question 28 , with 84 correct answers. This question is about using wipes and measuring knowledge about the challenges associated with sustainable use that impact water. It reflects the good results of previous educational campaigns on this aspect that Aguas de Huelva carried out among its client households before the survey [27].

However, we again detect the same trend as in the block on the stage of sewerage networks. The correct answers fall to almost half (46 correct answers) in question 27, which measures water regeneration knowledge compared to question 28.

There is one fact that is striking: The number of correct answers in questions 19, 20, and 26 is of the same order of magnitude (14,17, and 18 respectively). The first two measure the knowledge of the origin of the water (catchment), while number 26 measures the knowledge of the physical place where sewage is taken (purification). 
The water catchment stage presents the least number of correct answers, and therefore, the highest level of ignorance on the part of the households. The stages of treatment and regeneration and use present a higher number of correct responses and a greater knowledge of these stages.

Regarding the needs, values, and identity regarding water, question 13 of the survey reflects the household's state of opinion. To extract useful information from the data in this question, it is necessary to reduce the number of variables to be handled to facilitate their interpretation. For this purpose, a factor analysis by maximum likelihood with the principal components' extraction is applied to each block. This analysis allows us to pass to a new set of variables, which maintains the original variables' full information, which enjoy the advantage of being uncorrelated with each other and can be ordered according to the incorporated information. In all the rotated component matrices that appear in this paper, the following methods have been applied:

1. Extraction method: A principal component analysis.

2. Rotation method: Varimax with Kaiser normalization.

The results obtained are shown in Table 1:

Table 1. Rotated component matrix for question 13. (Source: Authors).

\begin{tabular}{|c|c|c|c|}
\hline & \multicolumn{3}{|c|}{ Components } \\
\hline & 1 & 2 & 3 \\
\hline Receive More Information & & & 0.829 \\
\hline Social Bonuses & & & 0.710 \\
\hline Origin of Water & 0.885 & & \\
\hline Good Taste of Water & 0.886 & & \\
\hline Have Healthy Water & 0.815 & & \\
\hline Reduce Number of Service Cuts & & 0.848 & \\
\hline Receive Water Leak Notices & 0.819 & & \\
\hline Water Availability With Greater Pressure & & 0.861 & \\
\hline Minimize Flood Effects & & 0.857 & \\
\hline Invest in Reclaiming and Harvesting Water & 0.523 & & \\
\hline
\end{tabular}

The explained variance is $69 \%$, which indicates that the original variables are arranged into three groups represented by the three principal components or factors obtained; and that they do sufficiently explain the needs and values of households. We performed the Kaiser, Meyer, and Olkin (KMO) test to assess whether the factor model (or the extraction of factors) as a whole is significant (high relationship between variables). The $\mathrm{KMO}$ obtained is 0.773 , which indicates that the relationship between variables is high and, therefore, the factor model is significant.

Bartlett's sphericity test evaluates the applicability of factor analysis of the variables studied. The model is significant if Significance $(p$-value) $<0.05$, indicating that factor analysis can be applied. This is the case.

Based on each variable's weights in the factors, it can be determined that each component obtained, in some way, explains aspects of water that household's value. Thus, we can name each of the factors as follows:

1. Component $1=$ Quality of service/health. The weight is given more in aspects related to water quality and its impact on health. This is the component with the highest variance and therefore explains what households value most.

2. Component $2=$ Quality of infrastructure. It collects information on the valuation of aspects related to the quality of the water network's infrastructure.

3. Component $3=$ Customer Relationship Management (CRM). It expresses the value of the household's relationship with the water company. In some way, it measures the service brand [17] of Aguas de Huelva among households and the importance they give to it, and therefore the trust 
they could have in the face of engagement actions to propose to them in later stages of the project. It presents the smallest variance.

The results obtained allow evaluating the individuals' attitudes that make up the sample with respect to different water aspects:

1. Attitude towards water consumption efficiency: Given by the data in question 15 .

2. Attitude towards the adoption of technological devices in the home related to water: extracted from the data of question 16 .

3. Attitude towards reclaimed water in the home: Given by data from questions 17 and 18 .

Once again, to extract useful information from these questions' data, it is necessary to reduce the number of variables to handle to facilitate interpretation. For this purpose, a block processing is applied, applying to each one the factor analysis by maximum likelihood.

The data from question 15 represent the measure of the home improvement attitude regarding its possibility of improvement concerning water consumption. We proceed to apply factor analysis with the extraction of principal components, obtaining the values shown in Table 2.

Table 2. Rotated component matrix for question 15. (Source: Authors).

\begin{tabular}{lcc}
\hline & Components & \\
\hline & $\mathbf{1}$ & $\mathbf{2}$ \\
Bathtub \& Shower & & 0.717 \\
Washing Machine & 0.520 & 0.704 \\
Dishwasher & & 0.765 \\
Toilet & 0.830 & \\
Household Cleaning & 0.818 & \\
Cooking & 0.795 & \\
\hline
\end{tabular}

As in the previous point, the explanation of the results shows that the two principal components obtained explain the attitude towards improving water use efficiency in the home since the explained variance is $66 \%$. The resulting $\mathrm{KMO}$ is 0.761 , and the Bartlett sphericity test is $p=0.000$ (significant model).

Although putting labels on the interpretation, in this case, is not so simple, it can be said that households show a more favorable attitude towards improving water use, grouping actions around two groups:

1. Component $1=$ General efficient use. There is an association of variables that would explain a general use to improve the efficiency of water in the home.

2. Component 2 = Efficient use in cleaning. A group associated with a field of improvement in water use in personal or household cleaning tasks.

When carrying out the KMO contrast (Kaiser, Meyer, and Olkin) and the Bartlett and sphericity test, it is verified that the factorial model as a whole is significant and applicable to the analyzed variables.

The data from question 16 represent the measure of attitude regarding the adoption of technological devices in the home. We proceed to apply factor analysis with the extraction of principal components, obtaining the values shown in Table 3. 
Table 3. Rotated component matrix for question 16. (Source: Authors).

\begin{tabular}{lc}
\hline \multicolumn{2}{c}{ Component } \\
\hline & $\mathbf{1}$ \\
Shower Heads & 0.631 \\
Acoustic Warning Devices & 0.866 \\
Smart Meters & 0.853 \\
Rainwater Regeneration & 0.884 \\
\hline
\end{tabular}

In this case, only one principal component was obtained with an explained variance of $65 \%$. To the KMO test (with a value of 0.787 ) and the Bartlett test with results that validate the model, an additional test has been added, the so-called Cronbach's Alpha test, obtaining a value of 0.825 ; indicating that the reliability of the measurement scale that we determined a priori is high. The component obtained will be called:

Component $1=$ Water saving devices. It will contain all the variables except Faucet flow limiters. This variable is not significant, and therefore, we will not take it into account for our analyses.

The attitude towards reclaimed water in the home is shown by the results obtained from the analysis of the answers to questions 17 and 18 .

The data in question 18 do not admit factor analysis since the question was not designed with a scale in its possible answers (Likert scale).

Therefore, we applied factor analysis to question 17, obtaining the results shown in Table 4.

Table 4. Rotated component matrix for question 17. (Source: Authors).

\begin{tabular}{lcc}
\hline & \multicolumn{2}{c}{ Components } \\
\cline { 2 - 3 } & $\mathbf{1}$ & $\mathbf{2}$ \\
\hline Reclaimed Water for Toilet & 0.875 & \\
Reclaimed Water for Washing Machine & 0.631 & \\
Reclaimed Water for Garden Irrigation & 0.752 & 0.898 \\
All Previous Cases at a Lower Price & & \\
No Case & -0.569 & \\
\hline
\end{tabular}

The explained variance is $63 \%$, with two groups of significant variables through two principal components:

1. Component $1=$ Reclaimed water for washing machine, toilet, garden, and no case

2. Component $2=$ All previous cases at a lower price

Although the Bartlett test is acceptable $(p=0.000)$, the KMO test gives a low result (0.595), although valid (close to 0.6 ), so another analysis is performed to seek to improve the factor analysis with the introduction of the extracted components that measure the attitude of households; in this case, the KMO improved with all of them. In other words, all the factors/components that summarize the attitude described in question 15 (General efficient use, Efficient cleaning use), 16 (Water saving devices), and question 17 itself have been introduced, (reclaimed water for washing machine, toilet, garden, and no case, all previous cases at a lower price), obtaining the results shown in Table 5.

The KMO test again gives a very low result (0.363), clearly insufficient (below 0.5$)$, indicating that the component extraction model is not valid in this case (with all components/factors) and does not record a valid relationship between the factors entered.

Therefore, for question 17, the two principal components extracted are taken: Reclaimed water for Washing Machine, Toilet, Garden, and No case, All the previous cases at a lower price. 
Table 5. Rotated component matrix. (Source: Authors).

\begin{tabular}{lccc} 
& \multicolumn{3}{c}{ Components } \\
\cline { 2 - 4 } & $\mathbf{1}$ & $\mathbf{2}$ & $\mathbf{3}$ \\
\hline General Efficient Use & & 0.819 & 0.879 \\
$\begin{array}{l}\text { Efficient Cleaning Use } \\
\text { Water Saving Devices }\end{array}$ & 0.861 & & \\
$\begin{array}{l}\text { Reclaimed Water for Washing Machine, } \\
\text { Toilet, Garden and No Case }\end{array}$ & & -0.711 & \\
All Previous Cases at A Lower Price & 0.799 & & \\
\hline
\end{tabular}

Regarding the results obtained from question 18:

1. 26 households found it indifferent to have their own rainwater regeneration system in their home/community, with the maximum technical guarantees of quality and safety

2. Six households would not accept to use reclaimed water in their home/community.

3. 43 households would agree to use reclaimed water for washing machine, toilet, and irrigation.

4. 22 households would agree to use reclaimed water for other household uses as well.

Finally, households' clusterization has been carried out (grouping of data with similar characteristics) [10]. The objective is to implement differentiated future strategies, designed and personalized towards each type of household (cluster) to change, reinforce, or eliminate current attitudes and behaviors in efficient water use. To design these strategies, we will use different DT techniques, such as product service systems (PSS) or design for behavior, which ensure the sustainability of the designed product or service [43]. The aim is to achieve a more significant commitment from households (engagement) regarding water. The following factors have been considered for the chosen clustering [10]:

1. Range of knowledge.

2. Principal factors or components of needs and values.

3. Principal factors or components of attitude regarding water consumption efficiency.

4. Principal factors or components of attitude regarding the adoption of technological devices in the home related to water.

5. Principal factors or components of attitude regarding the use of reclaimed water in the home and codification of question 18 .

An analysis has been performed taking the previous clusters with the variables defined below that characterize households:

1. Block of demographic characteristics.

2. Block of household characteristics, consumption range, and zone or district of Huelva.

3. Block of life experiences and psychosocial factors:

The clustering method is hierarchical (Euclidean squared distance and Ward method), obtaining three clusters characterized by:

1. Cluster 1:

a. High knowledge about the integral water cycle.

b. They value having a good quality of the infrastructure of the water network.

c. They do not particularly value the rest of the other two factors of the analysis.

d. Moderate attitude towards improving water consumption efficiency concerning toilet use, cleaning the home and kitchen. They do not believe that in other uses they can achieve greater efficiency (bath, washing machine, and dishwasher). 
e. Positive attitude towards the use of water-saving devices. Most choose to have the water company give the devices to them, although a household would accept spending up to 30 euros of the total limit.

f. Positive attitude towards the use of reclaimed water in the home (washing machine, toilet, and garden) if it is at a lower price than the current price for the same uses.

g. They are also inclined to adopt their own rainwater regeneration system in their home/community for washing machines, toilets, or garden uses, or even some other use.

2. Cluster 2:

a. Low knowledge of the integral water cycle.

b. They value a perceived good service moderately, in the form of perceived water quality and the absence of problems in the water service delivered to the home.

c. They value having a good quality of the infrastructure of the water network.

d. Negative attitude towards improving water consumption efficiency concerning toilet use, cleaning the home, and the kitchen. Nor do they believe that in other uses they can achieve greater efficiency (bath, washing machine, and dishwasher).

e. Negative attitude towards the use of water-saving devices.

f. Negative attitude towards the use of reclaimed water in the home (washing machine, toilet, garden).

g. However, they are very sensitive to the price of water and its possible drop.

h. Moderate/indifferent attitude to adopt their own rainwater regeneration system in their home/community for washing machines, toilets, or garden uses.

3. Cluster 3:

a. Average knowledge of the integral water cycle.

b. They value a perceived good service positively, in the form of perceived water quality and the absence of problems in the water service delivered to the home.

c. They value positively having information from the water company and how it relates to households.

d. Positive attitude to achieve greater efficiency in the use of water in bathtubs, washing machines, dishwashers. They do not believe that they can improve water consumption efficiency, concerning the use of the toilet, cleaning the home, and the kitchen.

e. Negative attitude towards the use of water-saving devices in the home.

f. Positive attitude towards the use of reclaimed water in the home (washing machine, toilet, garden), regardless of whether a lower price of water is achieved.

g. Indifferent attitude to adopt their own rainwater regeneration system in their home/community for washing machines, toilets, or garden uses.

Raw data used to characterize each cluster are too big to include in this paper, so we prefer to include the following case processing summary table (Table 6). 
Table 6. Case processing summary (Source: Authors).

\begin{tabular}{|c|c|c|c|}
\hline & & $\mathbf{N}$ & $\%$ MARGINAL \\
\hline \multirow{3}{*}{ Clusters } & High knowledge & 45 & 46.4 \\
\hline & Low knowledge & 21 & 21.6 \\
\hline & Average knowledge & 31 & 32.0 \\
\hline \multirow{5}{*}{ Age } & From 18 to 30 years & 4 & 4.1 \\
\hline & From 31 to 40 years & 16 & 16.5 \\
\hline & From 41 to 50 years & 32 & 33.0 \\
\hline & From 51 to 65 years & 39 & 40.2 \\
\hline & More than 65 years & 6 & 6.2 \\
\hline \multirow{2}{*}{ Gender } & Male & 66 & 68.0 \\
\hline & Female & 31 & 32.0 \\
\hline \multirow{4}{*}{ Education } & No Studies & 2 & 2.1 \\
\hline & Basic Studies & 24 & 24.7 \\
\hline & Bachelor & 35 & 36.1 \\
\hline & University Studies & 36 & 37.1 \\
\hline \multirow{4}{*}{ Income } & Less than $10,302 € /$ year & 20 & 20.6 \\
\hline & From $10,302 €$ to $25,000 € /$ year & 43 & 44.3 \\
\hline & From $25,000 €$ a 50,000 €/year & 26 & 26.8 \\
\hline & From $50,000 €$ a $100,000 € /$ year & 8 & 8.2 \\
\hline \multirow{4}{*}{ Occupation } & Unemployed & 13 & 13.4 \\
\hline & Employed & 55 & 56.7 \\
\hline & Self-Employed & 15 & 15.5 \\
\hline & Retired & 14 & 14.4 \\
\hline \multirow{3}{*}{ Children } & No Children & 57 & 58.8 \\
\hline & 1 & 24 & 24.7 \\
\hline & 2 & 16 & 16.5 \\
\hline \multirow{3}{*}{$\begin{array}{l}\text { Water } \\
\text { Consumption }\end{array}$} & Low & 30 & 30.9 \\
\hline & Average & 57 & 58.8 \\
\hline & High & 10 & 10.3 \\
\hline \multirow{6}{*}{ District } & Zone 1 & 29 & 29.9 \\
\hline & Zone 2 & 16 & 16.5 \\
\hline & Zone 3 & 13 & 13.4 \\
\hline & Zone 4 & 3 & 3.1 \\
\hline & Zone 5 & 18 & 18.6 \\
\hline & Zone 6 & 18 & 18.6 \\
\hline
\end{tabular}

In order to keep household confidentiality, an ID to identify each one has been used:

1. Cluster 1, in total, 45 households. They are from h1 to h13 (both included), h16, h17, h19, h21, h22, h24, h25, h26, h28, h31; from h34 to h37 (both included), h39, h41, h43, h45, h47, h51, h53, h54, h55, h61, h72, h74, h79, h81, h96, h98, h104, and h105.

2. Cluster 2, with 21 households. They are h14, h15, h18, h23, h27, h29, h30, h32, h38, h42, h44, h49, h50, h62, h77, h78, h82, h87, h88, h95, and h100.

3. Cluster 3, in total, 31 households. They are h33, h46, h48, from h56 to h59 (both included), h60, from h63 to h68 (both included), h71, h73, h75, h76, from h83 to h86 (both included), from h89 to h93 (both included), h97, h101, h102, h103.

The grouping followed by an iterative process (hierarchical) is shown graphically in the following dendrogram in Figure 3 (it is cut into three branches, at level 15): 


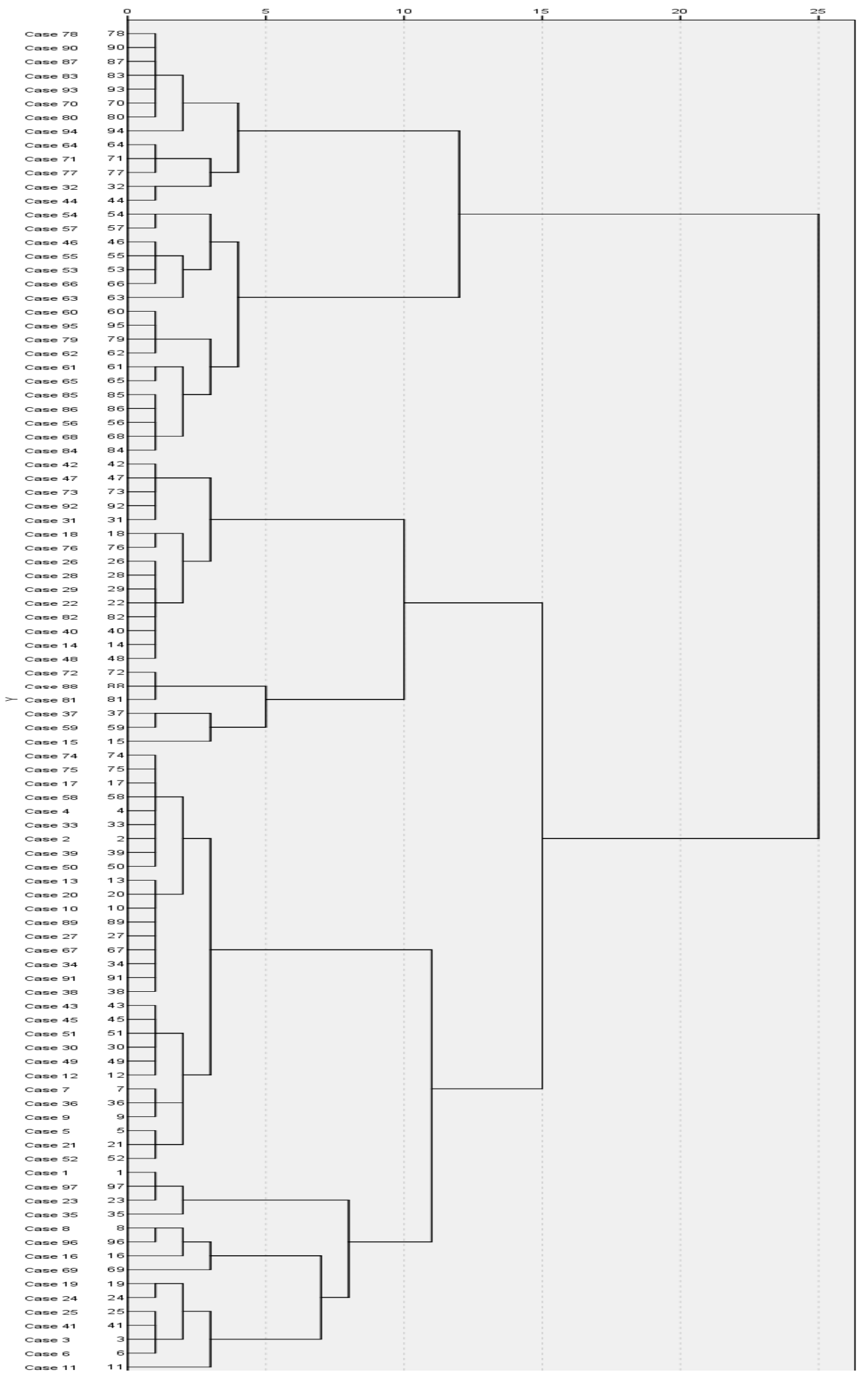

Figure 3. Dendrogram. (Source: Authors). 
We verify the adequacy of the clustering model applied to our data sample. That is, we are going to verify if the clusters obtained discriminate well enough. For this, we carried out an analysis of variance through ANOVA, using the results of the knowledge questions about the distribution network, sanitation, and sewerage network, obtaining the results shown in Table 7.

Table 7. ANOVA (Source: Authors).

\begin{tabular}{lllll}
\hline Distribution & \multicolumn{5}{l}{} \\
\hline & Sum of Squares & Root Mean Square (RMS) & F & Significance \\
Among Groups & 9.794 & 4.897 & 34.561 & 0.000 \\
Within Each Group & 13.319 & 0.142 & & \\
Total & 23.113 & & & \\
Sanitation & & & 20.003 & 0.000 \\
\hline Among Groups & 5.681 & 2.841 & & \\
Within Each Group & 13.350 & 0.142 & & \\
Total & 19.031 & & 5.448 & \\
Sewerage Networks & & & & \\
\hline Among Groups & 0.762 & 0.381 & & \\
Within Each Group & 6.578 & 0.070 & & \\
Total & 7.340 & & & \\
\hline
\end{tabular}

In all three cases, we obtain sufficiently high $\mathrm{F}$ and significance less than 0.05 , which indicates that the cluster results obtained discriminate well and are therefore valid.

We then carry out multinomial logistic regression tests to determine if the model obtained has the explanatory capacity, that is, if it is statistically significant and can be used to predict "the classification" of future data in the defined clusters. The statistics obtained in different tests are:

1. The goodness of fit.

2. Pseudo R squared.

3. Likelihood ratio tests.

4. Parameter estimates of the three clusters (two-to-two).

The results of Chi-squared (high), Pseudo R squared $(<1)$, significant and two-to-two parameter estimates give the model obtained as good in terms of prediction of classification of new samples.

\section{Discussion}

We would like to begin this section with a critical analysis of the limitations of this research. A first issue to review is the difficulties we had in achieving a diverse and sufficient number of participating households, since "Locating restless users for your cooperating user pool may not be easy; however, they are extremely helpful. Regular users are needed as well. They are able to share with the team reasonable and useful perspective on what is present in an alternative. However, a restless user will also guide the design team deeper into the problem domain or suggest things not previously considered. A challenge is to find a diverse set of restless users" [44]. However, with the participation of the 97 households which answered the survey, "we believe that this last point has been achieved, by minimizing the effect of uncertainty, the personal preferences of each household, the possible errors in obtaining household data, misunderstandings in language and communication with households, and inconsistencies, among others. In any case, the experience can be scaled in the future to all households in Huelva, using different ICT solutions, such as BDA and inference of future behaviors of homes such as through AI" [9]. The number of households is in line with other research projects [28-33], although we would have liked to have more households. In any case, the project design can be scaled to a greater number of households.

A second point is the limited number of participating households that had Smart meters; only 9 out of 97. We would have liked to have a greater number, but the deployment of Smart meters in 
the city of Huelva was limited to only a few hundred. This would have allowed us to compare the proactivity of households when measuring their interest in consulting their consumption on line and on real time.

Besides, we would have liked to include households that had smart and water-saving devices already installed, as in Lee et al. [1]. In this way we could have verified the effectiveness of the WDM strategies against households that did not have them.

Another point to criticize is the order followed when preparing the questionnaire. For logistical, temporary, and organizational reasons of the Aguas de Huelva company, we have been limited to elaborating the questions from the bibliographic review of similar projects and from the opinion of the company's experts. We would have liked to have had a previous workshop with households, where we could have gathered prior qualitative information about their interests, values, and needs. This would have been a previous step that would have improved the quality of the questionnaire, especially in the style of language to be used on the more technical questions about the knowledge of the integral water cycle.

A greater number of indicators could have been included, not only those referring to engagement based on knowledge, values, and needs, but it would have complicated the design and extension of the survey. This extension of the research may be left for future stages.

A critical point to analyze is that the responses to the questionnaire collect attitudes, needs, and values declared by households regarding water. The later stages of the DT methodology, through the implementation of the web-based prototype, should lead us to check whether what the households declare is based on a reality or on a false perception of their relationship with water.

Regarding the analysis of the results that serve as a basis to cover the stages of needfinding and synthesis of the DT framework used [20], we can state the following:

1. Regarding the knowledge that Huelva households have about the integral water cycle, there is a disproportion between the correct answers to questions 23 and 24. There were only eight correct answers for question 24 . However, 71 households answered correctly to question 23 . The combination of both questions measures the knowledge of the stage of sewerage networks. The disproportion may lie in question 24, which is a question that requires more technical and specific knowledge, while question 23 is more general.

2. The question with the highest number of positive responses is question 28 . This question is about using wipes and measuring knowledge about the challenges associated with sustainable use that impact water. It was included at the request of Aguas de Huelva and it reflects the good results of previous educational campaigns that the water company carried out on dates prior to the survey [27]. In light of this past success, it seems logical to think that it can serve as a way forward in implementing subsequent educational campaigns among Huelva's households.

3. Again, there is a disproportion between the correct answers in question 27, which measures water regeneration knowledge, compared to question 28 . The correct answers fall by almost half (46 correct answers) in question 27, compared to 84 correct answers in question 28 . It seems logical to think again that when questions have a technical content, the number of correct answers is reduced, although they are part of the same block of knowledge, in this case, the block on regeneration and sustainable use.

4. The pattern is repeated with the debugging block (questions 25 and 26), where there is a disparity between the number of correct answers to the two questions that are part of it.

5. On the results of the questions that measure the knowledge of the origin of the water (collection) and of the physical place where the water is poured at the end of the cycle (purification), the number of correct answers is very low (14 and 17) it seems that households do not have sufficient knowledge of where the water they consume comes from and where it goes. To these aspects of the cycle it seems that they give a "magical" character as if the water appeared and disappeared on a whimsical basis. Perhaps it is due to the fact that, in both cases, origin and completion, the physical place occupied by 
water, that of the environment of nature, is the furthest from the city, something that is seen as alien from the perspective of the city.

6. It is the catchment stage, which presents the least number of correct answers, and therefore, the greatest ignorance on the part of the households. In line with the previous point, we can propose It would require a more significant effort with educational campaigns on this stage, linked to the natural environment.

7. The stages of treatment and regeneration and use present a greater number of correct responses and, therefore, a better knowledge of these stages. Since there are several studies that link a positive attitude with high prior knowledge about water issues, among them that of Dean et al. [10], we can deduce that the knowledge about these stages can be related as the basis for the good aptitude that Huelva's homes have regarding the use of reclaimed water at home.

8. Regarding the needs and valuation that households have regarding water, from the statistical processing of the data, we can interpret that in general, households will be more likely to positively value actions that improve the quality of service with an impact on health. This is reflected in the factor analysis whose principal Component 1 is Quality of service/health from question 13 (Table 1). We understand the service as a perceived service (visualized) in the form of perceived water quality and absence of problems in the service delivered to the home.

9. They will value having a good quality of the water network infrastructure. According to the values of the principal Component $2=$ Quality of infrastructure from question 13 (Table 1).

10. They value the information from the water company and how it relates to households. In other words, in some way, they are qualifying the importance they attach to the company's service brand, and that conditions their trust with respect to it. It follows from the principal Component $3=$ Customer Relationship Management (CRM) of question 13 (Table 1).

11. Regarding the aspects of better water use that households detect to improve, we can conclude that, in general, households are aware of and are willing to apply strategies for better water use in a combination of actions on toilet use, home, and kitchen cleaning. These three variables are highly associated being collected in the principal component general efficient use, which is the principal component of question 15 (Table 2). To a lesser extent, the variable on a more efficient use of the washing machine is. It seems that households would favor receiving advice in these areas that would allow them to improve.

12. Regarding the attitude towards the use of reclaimed water in households, reflected by question 17 , the conclusion that can be drawn from it is that households have a majority favorable attitude towards the use of reclaimed water for washing machines, toilets, and gardens, but provided it is at a lower price than what they currently pay for said water. The economic factor is an important component in the possible acceptance of water regeneration technologies in the home for the described uses (washing machine, toilet, garden).

13. Regarding the acceptance of new technologies in the home, which help to better use water in it, we can say that it seems that households do not accept the incorporation of flow limiters in taps, perhaps due to their involvement in the invasion of their decision-making power or in restricting their freedom. In any case, it seems clear that acoustic limiters and smart meters that are devices that can provide them with information on their consumption would be highly valued. This follows from the fact that the principal Component 1 = Water saving devices, from question 16 (Table 3) contains all the variables except faucet flow limiters. This variable is not significant, and therefore, we will not take it into account for our analyzes.

14. There is an overwhelming majority (65 households out of 97) who would agree to have its own rainwater regeneration system in their home/community regarding the use of water reuse and regeneration systems. Besides, the most notable is that there is hardly any opposition (only six households out of 97) to having its own rainwater regeneration system, which opens a field for the introduction of this type of technology in the households served by Aguas de Huelva. 
15. The data have been processed several times, obtaining different numbers of clusters in each process, all of them valid. The one we propose here has finally been chosen, following the criterion of establishing a trade-off between having a high number of clusters that would allow highly targeted and customized field actions (experiments) to very particular segments of households (and therefore with greater efficacy of results). However, that would complicate the fieldwork related to the households (increasing the cost and the time of execution of the experiments). Considering a lower number of clusters (two), it would be easier to carry out the subsequent fieldwork with the households, but it would be less effective in its results by allowing less customization of subsequent households' actions. We believe that we have chosen the best option of selecting three clusters, which discriminates sufficiently and facilitates subsequent interaction with households. Furthermore, this number of clusters is in line with similar research in other parts of the world [10].

16. A clusterization has been attempted according to Huelva's districts, and a clear differentiation has not been achieved either. The maximum obtained were two clusters with the data very grouped between them, which provided little real knowledge and little discrimination. This has allowed us to confirm what Aguas de Huelva had already told us in previous discussions: The great social homogeneity between the city's different areas/districts. In other words, the district to which the home belongs is not decisive, nor does it explain the questions that this research tries to answer.

17. Beyond the interpretation of the clusterization results, we can extract knowledge and imagine possible actions to be carried out. These actions should be based on DT for future field experiments to provoke real changes through PSS [45] or design for behavior strategies and methods [43].

18. Finally, we have obtained only results that add valid scientific information about this research's objectives, beyond the information obtained from the simple statistical exercise, adding and treating all the variables and components described above.

As future lines of research, we would like to propose a first way, focused on determining the importance of technology in WDM strategies, especially the role of ICT facilitators and its possible impact on household engagement. These tools will be used as support:

a. If available, smart meters for later stages in DT, especially in the prototype and testing stages [20]. One of its benefits would lie in measuring, from the point of view of household management, the effectiveness of this tool, balancing it with the cost of its deployment. For more information on this technology, see Boyle et al. [46]. In this paper, numerous experiences are collected in different cities of Australia, New Zealand, and different international projects. All of them follow methodologies and scopes similar to those of our research.

b. A web-based prototype to test true customer behavior to face meanings proposal from the water utility.

c. Email as an extra communication channel with the client. Its use compared to other more traditional means, such as sending letters and information on paper, is another matter to be debated.

d. APPs for mobile phones, that allow a semi real-time interaction and better quality of information with the households, especially for consumption feedback.

As a second line of research, and as a continuity of the results published in this article, we are working on the statistical analysis of the data used to analyze the influence of the different variables and components/factors on household consumption ranges (high, medium, low). The statistical tools used are the "decision trees", using the classification and regression trees (CRT) method. This will allow us to know which variables/factors/independent components are the decisive ones regarding water consumption, as a quantitative expression of households' real behavior in efficient water use.

This approach will be complemented with subsequent workshops with households and with the design of a web-based prototype that allows actions to improve their engagement concerning water (experiments), according to the DT-based framework described in [9], which provides a clear idea of the qualitative behavior regarding water. 


\section{Recommendations}

From the points opened in the previous Discussion section, and in relation to improving the knowledge of households in Huelva about the integral water cycle, we can recommend a series of actions that, in some way, the web-based prototype [39] should incorporate such as:

1. Technical but informative and entertaining approach to the water path in the different blocks that make up the integral water cycle and its impact on the consumer. According to what we commented in the Discussion section, regarding the difference in correct answers between the more technical questions and those that, on the same topic, are less technical in writing, it is recommended to use a simpler, less technical language. Besides, whenever possible, visual support should be used to educate households about the integral water cycle, in the implementation of the web-based prototype.

2. Follow the communication style previously used in the campaign for the use of wipes in the Huelva water home [27], which had a positive impact among households, emphasizing the use of more straightforward language and attractive visual support through images or videos that can improve touch-points with households. These are critical elements within the DT where the value created between customers and the service company occurs [47].

3. Household education on the catchment stage, sewage, and purification networks, especially on the impact of water use on sources (source) and purification (discharge). We understand that the focus must be on reviewing Huelva's relationship and the sustainability of its closest natural environment, as other experiences have reviewed $[48,49]$. It is about replacing the magical character that households seem to give to the water service, with another concept that values more the water service and its connection with the city's environment.

4. Provide households with more information on the quality of the water and the network that supports the service, given the appreciation that households make of both.

5. As households value reclaimed water positively, it is considered that it would be an opportunity to try financing strategies, by Aguas de Huelva, for the installation of reclaimed water technologies in the home that promote their adoption.

6. The semantic dimension in our project is critical, so in the future prototype stage in our DT framework [20], the graphic part and the web-customer relationship interface are critical to generating our web-based prototype, with which to interact with households [39]. Wicked problems are too abstract [40]; therefore, there are many linguistic barriers to be able to communicate with precise words. Having an excellent graphical interface is essential for the success of the project. Therefore, it could be necessary to contract an agency specialized in web design [50].

7. To achieve greater household engagement regarding the efficient use of water, it is necessary to generate new messages and meanings about water combined with technology and ICT facilitators around water [51]. The goal is to create a radical vision about water, a new strategic meaningful direction with a high impact on households' water valorization [52].

8. Since the economic factor is a significant component in the possible acceptance of water regeneration technologies in the home, models based on the type of design produced by PSS should be considered. This can lead households to change their perception of water, going from models of technologies in the home based on device ownership to models based on access to the service that water provides for households (access-based wellbeing) [53]. In this new paradigm, the water company owns the technology that facilitates such service. From the water company's point of view, there would be an economic interest aligned with sustainability [54] in increasing the efficiency, durability, and reuse of the technology and materials involved in water service. This model aligns PSS with sustainability.

\section{Conclusions}

We would like to draw attention to several facts that act as essential conclusions to improve household engagement: 
1. Better knowledge about the integral water cycle of households explains households' positive aptitudes regarding the possibility of being aware of their capacity to improve on the use of water at home. This will also influence the availability of households to receive advice to help them use water more efficiently. Therefore, it is essential to improve household knowledge about the integral water cycle. It is reflected in the households belonging to cluster 1 , which have high knowledge and a good attitude.

2. A better knowledge also explains the positive predisposition of households towards reclaimed water. There is willingness to adopt technologies that enable reclaimed water use. This is conditioned to certain uses that represent economic savings in the home. Actions that involve more education on the use of regenerative water at home would help in Huelva so that households could easily adopt these technologies. It should be possible to complement it with financing and economic policies that would encourage their adoption with savings in the price that households pay for water. In line with what was obtained in the clustering.

3. The variables that measure the psychosocial factors corresponding to "Social activities around water" and "Participation in social organizations" (questions 11, and 12) are not significant. In other words, they do not explain, they do not discriminate, and they do not characterize the households participating in this survey. In conclusion, they are expendable.

4. The district to which the home belongs is not decisive, nor does it explain the questions that the investigation tries to answer. This shows the great social homogeneity among the city's different areas/districts.

5. The sensitization shown in general, although to a different degree of importance and appreciation, according to membership in each cluster by households in Huelva regarding water price. WDM strategies that use this lever can help regulate consumption and facilitate the adoption of new technologies to improve water use efficiency and technologies for the regeneration of water in the home.

6. The use of clustering as a mathematical tool has served to obtain three clusters of households with similar characteristics:

a. The first corresponds to households with high knowledge of the integral water cycle and a positive attitude to smart devices at home.

b. The second relates to households with insufficient knowledge of the integral water cycle and high sensitivity to price.

c. The third corresponds to households with average knowledge and a predisposition to have a closer relationship with the water company.

7. This classification allows the implementation of different WDM strategies tailored to each cluster. This implementation will be part of another later stage of the research, not described in this article, which will allow to achieve the ultimate objective of the project. This goal is to facilitate greater engagement of households concerning water and align citizens with the sustainability of their city.

The results obtained regarding the influence of the degree of knowledge on the integral water cycle and awareness regarding the price are in line with those obtained in other studies throughout the world, that appear cited in this paper.

However, the non-influence of social factors (activities and participation in organizations) and zonal factors (areas/districts) within the city do not follow what was obtained in other studies, like that of Dean et al. [10].

This paper's novelty lies in having a portrait of the starting point of the homes of an intermediary city (Huelva) in their relationship with water. It analyzes the characterization of the city's hydrosocial contract in its private behavior. Most other scientific research has focused on large cities that suffer from water stress, or even water scarcity, while in the case of Huelva, it is an intermediary city with 
low water stress. The absence of a sensation of scarcity does not act as a motivating lever among citizens to improve efficiency in water use. Without this motivating driver, the entire project's goal is to determine to what extent a more efficient and sustainable use of water can be achieved in households through strategies focused on managing demand (WDM) and not supply. To what extent is citizen's engagement regarding water possible, and what is the effectiveness of the levers proposed to achieve it?

Perhaps the methodology, material and means, and results presented in this research can serve as inspiration for other studies on household engagement with water, in a similar context. In particular, they could be applied to other intermediary cities with low water stress throughout the world.

Author Contributions: All authors participated directly in this research. Conceptualization, G.B.-M. and C.R.-M.; data curation, G.B.-M. and Y.M.N.-G.; formal analysis, G.B.-M. and Y.M.N.-G.; investigation, G.B.-M., C.R.-M., and Y.M.N.-G.; supervision, G.B.-M. and C.R.-M.; writing-original draft, G.B.-M. and C.R.-M.; writing-review and editing, G.B.-M., C.R.-M., and Y.M.N.-G. All authors have read and agreed to the published version of the manuscript.

Funding: This research received no external funding.

Acknowledgments: This study was partly supported by the Grupo Suez and Aguas de Huelva Water Company.

Conflicts of Interest: The authors declare that they have no conflicts of interest.

\section{Nomenclature}

$\begin{array}{ll}\text { AI } & \text { Artificial Intelligence. } \\ \text { ANN } & \text { Artificial Neural Networks. } \\ \text { ANOVA } & \text { Analysis of Variance. } \\ \text { BDA } & \text { Big Data Analytics. } \\ \text { CNMC } & \text { Comisión Nacional de los Mercados y la Competencia. (National Commission for } \\ \text { CRM } & \text { Markets and Competition) } \\ \text { CRT } & \text { Customer Relationship Management. } \\ \text { DT } & \text { Classification and Regression Trees } \\ \text { EM } & \text { Design Thinking. } \\ \text { ERG } & \text { Expectation Maximization. } \\ \text { ETSII } & \text { Existence, Relatedness, Growth. } \\ \text { ICT } & \text { Escuela Técnica Superior de Ingenieros Industriales. } \\ \text { ISUDS } & \text { Information and Communication Technologies. } \\ \text { KMO } & \text { Integrated Sustainable Urban Development Strategy. } \\ \text { PNCI } & \text { Kaiser-Meyer-Olkin. } \\ \text { PSS } & \text { Plan Nacional de Ciudades Inteligentes. (National Plan for Smart Cities) } \\ \text { SDG } & \text { Product Service Systems. } \\ \text { UPM } & \text { Sustainable Development Goals. } \\ \text { WDM } & \text { Universidad Politécnica de Madrid. }\end{array}$

\section{References}

1. Lee, M.; Tansel, B.; Balbin, M. Urban Sustainability Incentives for Residential Water Conservation: Adoption of Multiple High Efficiency Appliances. Water Resour. Manag. 2013, 27, 2531-2540. [CrossRef]

2. Mellouli, S.; Luna-Reyes, L.F.; Zhang, J. Smart government, citizen participation and open data. Inf. Polity 2014, 19, 1-4. [CrossRef]

3. Al-Dalou, R.; Abu-Shanab, E. E-participation levels and technologies. In Proceedings of the 6th International Conference on Information Technology (ICIT 2013), Amman, Jordan, 8-10 May 2013.

4. Szarek-Iwaniuk, P.; Senetra, A. Access to ICT in Poland and the Co-Creation of Urban Space in the Process of Modern Social Participation in a Smart City-A Case Study. Sustainability 2020, 12, 2136. [CrossRef]

5. Sæbø, O.; Rose, J.; Flak, L.S. The shape of eParticipation: Characterizing an emerging research area. Gov. Inf. Q. 2008, 25, 400-428. [CrossRef] 
6. Comisión Nacional de los Mercados y la Competencia (CNMC). Telecomunicaciones y Audiovisual. Informe Económico Sectorial (2019). ESTAD/CNMC/003/20. Available online: https://www.cnmc.es/sites/default/files/ 3083420_4.pdf (accessed on 15 July 2020). (In Spanish)

7. Plan Nacional de Ciudades Inteligentes. Available online: https:/www.red.es/redes/es/que-hacemos/ ciudades-inteligentes/plan-nacional-de-ciudades-inteligentes (accessed on 15 July 2020). (In Spanish)

8. Bermejo-Martín, G.; Rodríguez-Monroy, C. Sustainability and Water Sensitive Cities: Analysis for Intermediary Cities in Andalusia. Sustainability 2019, 11, 4677. [CrossRef]

9. Bermejo-Martín, G.; Rodríguez-Monroy, C. Design Thinking Methodology to Achieve Household Engagement in Urban Water Sustainability in the City of Huelva (Andalusia). Water 2020, 12, 1943. [CrossRef]

10. Dean, A.J.; Lindsay, J.; Fielding, K.S.; Smith, L.D.G. Fostering water sensitive citizenship-Community profiles of engagement in water-related issues. Environ. Sci. Policy 2016, 55, 238-247. [CrossRef]

11. Alderfer, C.P. An empirical test of a new theory of human needs. Organ. Behav. Hum. Perform. 1969, 4, 142-175. [CrossRef]

12. Strengers, Y. Smart Metering Demand Management Programs: Challenging the Comfort and Cleanliness Habitus of Households. In Proceedings of the 20th Australasian Conference on Computer-Human Interaction: Designing for Habitus and Habitat, Cairns, Australia, 8-12 December 2008; pp. 9-16.

13. Redgas. Available online: www.redgas.at (accessed on 15 July 2020). (In German)

14. Meyer, M.H.; Tucker, M.J. Innovating for effectiveness: Lessons from design firms. Res. Technol. Manag. 2010, 53, 21-28. [CrossRef]

15. Yan, W.; Roggema, R. Developing a Design-Led Approach for the Food-Energy-Water Nexus in Cities. Urban Plan. 2019, 4, 123-138. [CrossRef]

16. Pruneau, D.; Lang, M.; Kerry, J.; Langis, J.; Fortin, G.; Liboiron, L. Leaders of sustainable development projects: Resources used and lessons learned in a context of environmental education. J. Educ. Sustain. Dev. 2014, 8, 155-169. [CrossRef]

17. Marika, L.; Andreassen, T.W.; Clatworthy, S.; Hillestad, T. Innovating for Trust; Chapter 11: "Service Design Thinking"; Edward Elgar Pub: Cheltenham, UK, 2017; ISBN 9781785369476.

18. Ide, T.; Tubi, A. Education and environmental peacebuilding: Insights from three projects in Israel and Palestine. Ann. Am. Assoc. Geogr. 2020, 110,1-17. [CrossRef]

19. Hehn, J.; Uebernickel, F.; Herterich, M. Design Thinking Methods for Service Innovation-A Delphi Study. In Proceedings of the PACIS 2018, Yokohama, Japan, 26-30 June 2018; Available online: https: //aisel.aisnet.org/pacis2018/126 (accessed on 14 May 2020).

20. ME310. ME310 Design Innovation at Stanford University. 2010. Available online: https://web.stanford.edu/ group/me310/me310_2016/ (accessed on 15 July 2020).

21. Veenhoven, R. Happy life-expectancy. Soc. Indic. Res. 1996, 39, 1-58. [CrossRef]

22. Brundtland, G.H. World Commission on Environment and Development (WCED). Our Common Future 1987, 17, 1-91.

23. De Haan, F.J.; Ferguson, B.C.; Adamowicz, R.C.; Johnstone, P.; Brown, R.R.; Wong, T.H.F. The needs of society: A new understanding of transitions, sustainability and liveability. Technol. Forecast. Soc. Chang. 2014, 85, 121-132. [CrossRef]

24. Bourdieu, P. Habitus. In Habitus: A Sense of Place, 2nd ed.; Hillier, J., Rooksby, E., Eds.; Ashgate Publishing Ltd.: Hants, UK, 2005; pp. 43-49.

25. Knoeri, C.; Steinberger, J.K.; Roelich, K. End-user centered infrastructure operation: Towards integrated end-use service delivery. J. Clean. Prod. 2016, 132, 229-239. [CrossRef]

26. Available online: http://i2t.webs.upv.es/documentos/Reto2SUEZ.pdf (accessed on 15 July 2020). (In Spanish)

27. Aguas de Huelva. Available online: https://www.aguashuelva.com/retos-sociales-retos-compartidos/ (accessed on 15 July 2020). (In Spanish)

28. Newton, P.; Meyer, D. Exploring the Attitudes-Action Gap in Household Resource Consumption: Does Environmental Lifestyle Segmentation Align with Consumer Behaviour? Sustainability 2013, 5, 1211-1233. [CrossRef]

29. Dean, A.J.; Fielding, K.S.; Newton, F.J. Community Knowledge about Water: Who Has Better Knowledge and Is This Associated with Water-Related Behaviors and Support for Water-Related Policies? PLoS ONE 2016, 11, e0159063. [CrossRef] [PubMed] 
30. Willis, R.M.; Stewart, R.A.; Giurco, D.P.; Talebpour, M.R.; Mousavinejad, A. End Use Water Consumption in Households: Impact of Socio-Demographic Factors and Efficient Devices. J. Clean. Prod. 2013, 60, 107-115. [CrossRef]

31. Beal, C.D.; Flynn, J. Toward the digital water age: Survey and case studies of Australian water utility smart-metering programs. Util. Policy 2015, 32, 29-37. [CrossRef]

32. Fielding, K.S.; van Kasteren, Y.; Louis, W.; McKenna, B.; Russell, S.; Spinks, A. Using individual householder survey responses to predict household environmental outcomes: The cases of recycling and water conservation. Resour. Conserv. Recycl. 2016, 106, 90-97. [CrossRef]

33. Willis, R.M.; Stewart, R.A.; Panuwatwanich, K.; Williams, P.R.; Hollingsworth, A.L. Quantifying the influence of environmental and water conservation attitudes on household end use water consumption. J. Environ. Manag. 2011, 92, 1996-2009. [CrossRef]

34. Kujawińska, A.; Rogalewicz, M.; Diering, M. Application of expectation maximization method for purchase decision-making support in welding branch. Manag. Prod. Eng. Rev. 2016, 7, 29-33. [CrossRef]

35. Wierzbicka, W. Socio-economic potential of cities belonging to the Polish National Cittaslow Network. Oeconomia Copernic. 2020, 11, 203-224. [CrossRef]

36. Sakao, T.; Neramballi, A. A Product/Service System Design Schema: Application to Big Data Analytics. Sustainability 2020, 12, 3484. [CrossRef]

37. Verganti, R. Design, Meanings, and Radical Innovation: A Metamodel and a Research Agenda. J. Prod. Innov. Manag. 2008, 25, 434-456. [CrossRef]

38. Verganti, R. Design as brokering of languages: The role of designers in the innovation strategy of Italian firms. Des. Manag. J. 2003, 3, 34-42.

39. Potthoff, T.; Siemon, D.; Wilms, K.; Möser, S.; Hellmann, M.; Stieglitz, S.; Robra-Bissantz, S. Collaborative Service Blueprinting for Design Thinking: Evaluation of a Digital Prototype. In Proceedings of the 51st Hawaii International Conference on System Sciences, Waikoloa Village, HI, USA, 3-6 January 2018; Available online: http://hdl.handle.net/10125/50467 (accessed on 14 May 2020).

40. Buchanan, R. Wicked Problems in Design Thinking. Des. Issues 1992, 8, 5-21. [CrossRef]

41. Instituto Nacional de Estadística. Available online: https://www.ine.es/prensa/np934.pdf (accessed on 15 July 2020). (In Spanish)

42. United Nations Department of Economic and Social Affairs (UNDESA). Available online: https://www.un. org/waterforlifedecade/index.shtml (accessed on 15 July 2020).

43. Young, G. Design Thinking and Sustainability. Available online: https://zum.io/wp-content/uploads/2010/06/ Design-thinking-and-sustainability.pdf (accessed on 15 July 2020).

44. Tannian, M.F. Embracing Quality with Design Thinking. In The Future of Software Quality Assurance; Goericke, S., Ed.; Springer: Cham, Switzerland, 2020; pp. 161-174. [CrossRef]

45. Haemmerle, L.; Shekar, A.; Walker, D. Key concepts of radical innovation for sustainability, with complementary roles for industrial design and engineering. Int. J. Sustain. Des. 2012, 2, $24-45$.

46. Boyle, T.; Giurco, D.; Mukheibir, P.; Liu, A.; Moy, C.; White, S.; Stewart, R. Intelligent Metering for Urban Water: A Review. Water 2013, 5, 1052-1081. [CrossRef]

47. Clatworthy, S. Bridging the gap between brand strategy and customer experience. Manag. Serv. Qual. 2012, 22, 108-127. [CrossRef]

48. Hussein, H. A critique of water scarcity discourses in educational policy and textbooks in Jordan. J. Environ. Educ. 2018, 49, 260-271. [CrossRef]

49. Pruneau, D.; El Jai, B.; Khattabi, A.; Benbrahim, S.; Langis, J. Using design thinking and Facebook to accompany women in solving water problems in Morocco. In Handbook of Sustainability Science and Research; World Sustainability Series; Filho, W., Ed.; Springer: Berlin, Germany, 2018.

50. Enfoque Comunicación. Available online: www.enfoquecomunicacion.com/ (accessed on 15 July 2020). (In Spanish)

51. Dell'Era, C.; Marchesi, A.; Verganti, R. Mastering Technologies in Design-Driven Innovation. Res. Technol. Manag. 2010, 53, 12-23. [CrossRef]

52. Dell'Era, C.; Magistretti, S.; Cautela, C.; Verganti, R.; Zurlo, F. Four kinds of design thinking: From ideating to making, engaging, and criticizing. Creat. Innov. Manag. 2020, 29, 324-344. [CrossRef] 
53. Manzini, E. Context-based wellbeing and the concept of regenerative solution: A conceptual framework for scenario building and sustainable solutions development. J. Sustain. Prod. Des. 2002, 2, 141-148. [CrossRef]

54. Shapira, H.; Ketchie, A.; Nehe, M. The integration of Design Thinking and Strategic Sustainable Development. J. Clean. Prod. 2017, 140, 277-287. [CrossRef]

Publisher's Note: MDPI stays neutral with regard to jurisdictional claims in published maps and institutional affiliations.

(C) 2020 by the authors. Licensee MDPI, Basel, Switzerland. This article is an open access article distributed under the terms and conditions of the Creative Commons Attribution (CC BY) license (http://creativecommons.org/licenses/by/4.0/). 